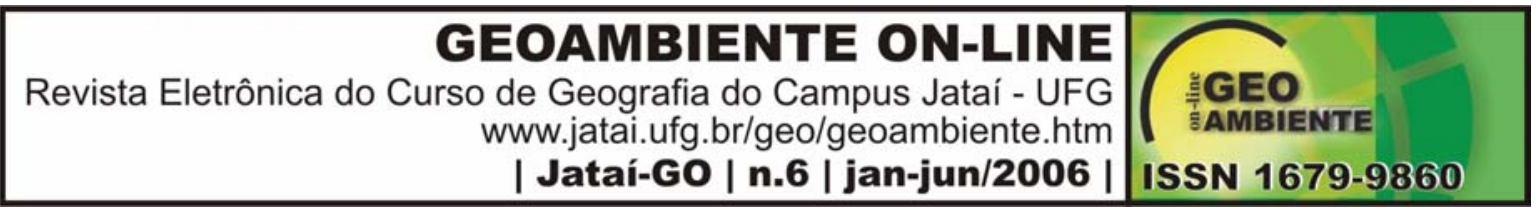

\title{
UMA ANÁLISE DO DESENVOLVIMENTO SUSTENTÁVEL
}

João Mateus de Amorim ${ }^{1}$ (1 - Professor de Geografia - Escola Agrotécnica Federal de Uberlândia, mateusamorim@,terra.com.br)

\section{RESUMO}

Este artigo faz uma análise do Desenvolvimento Sustentável com o objetivo de entender a sua relação com a sociedade e a natureza. Isso também permitirá estabelecer possíveis discussões com vistas ao entendimento das ações humanas sobre o espaço geográfico. O viés abordado está amparado na compreensão da conjuntura do Desenvolvimento Sustentável e do Crescimento Econômico. Conceituamos o Desenvolvimento utilizando as perspectivas do Produto Interno Bruto (PIB) e do Índice de desenvolvimento Humano (IDH), distinguindo Crescimento de Desenvolvimento. O PIB é de cunho estritamente econômico, enquanto que o IDH aponta um olhar mais amplo abarcando o aspecto social, ambiental, político e cultural. Na concepção do IDH há maiores oportunidades de promover qualidade de vida, cidadania e justiça social para toda a sociedade.

Palavras -Chave: Desenvolvimento Sustentável, crescimento econômico, pegada ecológica.

\begin{abstract}
AN ANALYSIS OF THE SUSTAINABLE DEVELOPMENT

This article analyses the Sustainable Development with the objective to understand its relationship with the society and the nature. This also will allow establishing possible discussions with the objective understand to human activities on the geographic space. The perspective of this view is supported by the understanding of the conjuncture of the Sustainable Development and the Economic Growth. We appraise the Development using the perspectives of Gross domestic product (GDP) and of the Human development Index (HDI) distinguishing Growth from Development. The GDP is of strict economic matrix,
\end{abstract}




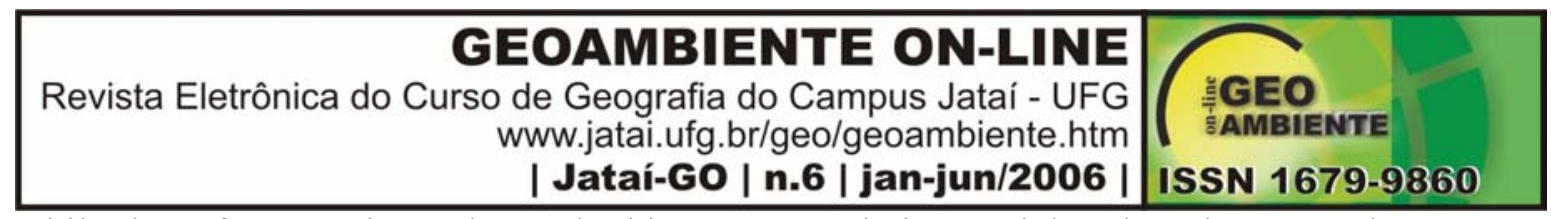

while that of HDI points a larger looking, contemplating social and environmental aspects as cultural and political one. HDI conception it has better chances to promote quality of life, citizenship and social justice for all the society.

Key words: Sustainable Development, Economic Growth, Ecological Footprint.

\section{Introdução}

[...] "quando a economia entra em cena, o meio ambiente pode ser ameaçado por novos tipos de ciclos de realimentação, tão complexos e perigosos quantos alguns encontrados na natureza" (GORE, 1993, p. 61).

“A cada ano são acrescentados mais 83 milhões de pessoas a terra [...] a maioria dessa população vive em cidades de países pobres ou em desenvolvimento, sob precárias condições ambientais - poluição, falta de saneamento básico, condições inadequadas de moradia e outros problemas" (DIAS, 2002 b: 53).

"A civilização industrial, como se encontra hoje organizada, está-se chocando frontalmente com o sistema ecológico do planeta" (GORE, 1993, p. 295).

Nesse artigo pretendemos analisar o Desenvolvimento na perspectiva do Índice de Desenvolvimento Humano (IDH) e do Produto Interno Bruto (PIB). O IDH mostra um retrato mais fiel da sociedade, como: qualidade de vida, renda per capta e educação, enquanto que o PIB restringe-se ao aspecto econômico. Devido a pouca preocupação com os aspectos socioambientais e a prioridade ao crescimento econômico, ocorrem, redução da qualidade de vida nos países subdesenvolvidos.

\section{Desenvolvimento na perspectiva do IDH, do PIB e da Sustentabilidade.}

O Desenvolvimento na perspectiva do IDH, do PIB e da Sustentabilidade determina a relação entre sociedade e meio ambiente. Como está o meio ambiente, principalmente nos países subdesenvolvidos com o 'pensamento único' no PIB? E o que fazer quando este Crescimento Econômico torna-se fórmula milagrosa de campanha política? Como relacionar o Crescimento Econômico, à natureza e à sociedade? O Crescimento Econômico 


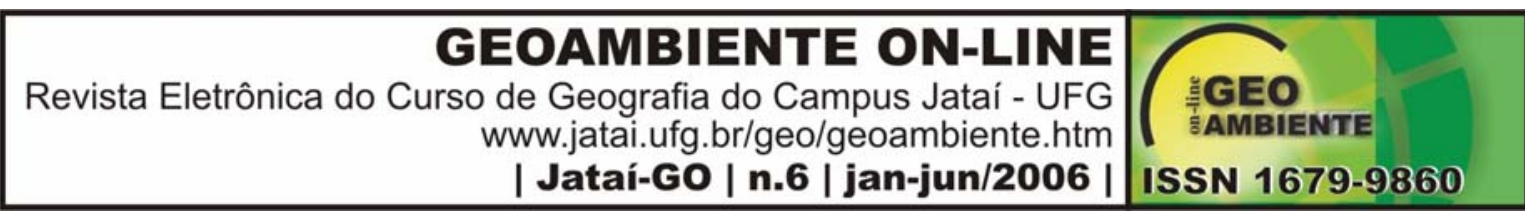

está concentrado no meio urbano, então, o que é preciso fazer para amenizar esse paradoxo entre o pequeno espaço ocupado pelas cidades e o alto consumo de recursos naturais?

E ainda mais que, "quase todo o Crescimento Econômico está ocorrendo em cidades que ocupam $2 \%$ da superfície da terra, mas consomem $75 \%$ de seus recursos. O aumento da eficiência em uma parte relativamente pequena do mundo produziu grandes resultados" (DIAS, 2002b: 55). “As cidades geram 75\% do gás carbônico que é despejado na atmosfera" (DIAS, 2002b: 55). Podemos afirmar que elas são frutos do Desenvolvimento, da produção, da biotecnologia, da industrialização, da urbanização amparados pela cultura consumista da civilização moderna. Sendo assim, o que podemos fazer para reverter o quadro ora apresentado?

O que tem sido feito para mudar isto? [...] Conferência de Estocolmo (Suécia, 1972) [...] a partir daí a preocupação com o ambiente tornou-se cada vez maior e a educação ambiental foi considerada como um dos instrumentos mais importantes para promover as mudanças que se faziam necessárias [...] Em 1992 [...] Rio-92 [...] saiu à agenda 21, um documento internacional de compromissos ambientais contendo recomendações para um novo modelo de desenvolvimento (Desenvolvimento Sustentável) e enfatizado a importância da educação ambiental (sic) (DIAS, 2002b: 60).

Com base nesses fatos e outros, Penteado (2000) discute o desacordo entre Desenvolvimento com base no (PIB) e Desenvolvimento na perspectiva do (IDH). O Desenvolvimento (PIB) colocou o Brasil em $37^{\circ}$ lugar no "Ranking" de 125 países no ano de 1992. Mas esta posição não mostra a qualidade de vida e nem a distribuição da riqueza, e somente o Crescimento Econômico. Nessa análise, ocorre uma distorção na realidade, pois a renda per capta média não condiz com a renda média do povo brasileiro que, na maioria das vezes, passa fome. "Enquanto que um grupo pequeno de pessoas está equiparado com países do $5^{\circ}$ lugar, há uma massa de pessoas fazendo parte dos países do final do "Ranqueamento" (grifo nosso). Já o Desenvolvimento segundo o IDH, em 1990, mostrou uma análise abrangendo a educação, a expectativa de vida e a renda per capta. A abordagem sobre o Desenvolvimento, somente na perspectiva do PIB mostrou-se insustentável tanto do ponto de vista Social como Ambiental. 


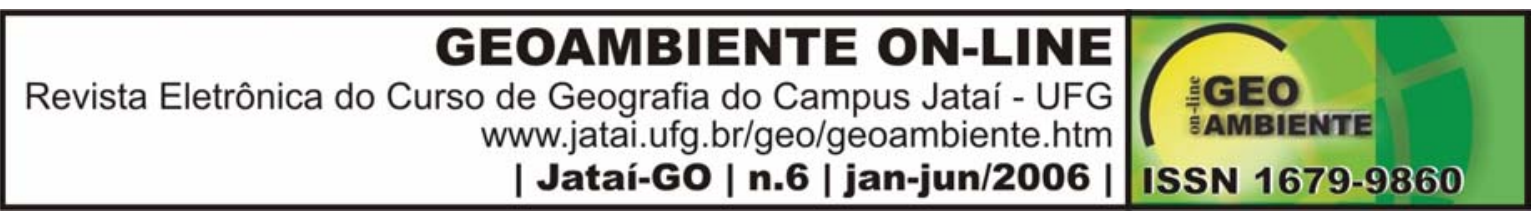

Os três pontos abordados pelo IDH, como: escola, saúde e economia mostram o verdadeiro Desenvolvimento, pois abrangem todas as dimensões do ser humano, que são: qualidade de vida, meio ambiente equilibrado, acesso às oportunidades de emprego, educação e cidadania. A análise do Desenvolvimento, com base no IDH, aponta o Brasil com a posição de $74^{\circ}$ lugar no "Ranking", que é a verdadeira colocação de um país desigual, concentrador e injusto com a sociedade mais pobre e a natureza.

De acordo com Penteado (2000) o processo de desenvolvimento alcançado pelo Brasil via transferência de indústrias e de tecnologia dos países ricos (desenvolvidos) de forma acelerada agrava os problemas socioambientais, principalmente dos espaços urbanos. Esse Desenvolvimento ocorreu de "fora para dentro", ou seja, sem a participação da população brasileira. Isso provocou a expulsão dos trabalhadores do campo, poluiu o meio ambiente, concentrou a população do campo nas cidades, empobreceu as populações rurais, pois com a mecanização no campo acirrou-se ainda mais a concentração fundiária pelos latifúndios (MÜLLER, 1989 ).

Segundo (Dias, 2002b), “entre os inúmeros problemas ambientais gerados pelo atual modelo de ‘desenvolvimento’ cabe destacar os seguintes” (DIAS, 2002b: 44):

- efeito estufa;

- alterações climáticas;

- buraco na camada de ozônio;

- alterações na superfície da terra;

- desflorestamento/queimadas;

- erosão do solo/desertificação;

- destruição de habitats;

- perda de biodiversidade (genética, de habitats, de ecossistemas);

- poluição (do ar, da água, do solo, sonora) etc;

- escassez de água potável;

- erosão da diversidade cultural;

- exclusão social [...] 


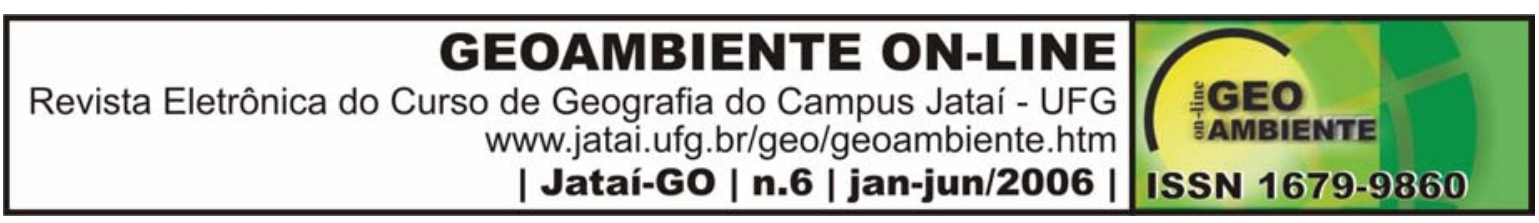

Segundo Gore (1993), os ciclos de realimentação desse processo estão pactuados na relação de dependência entre países subdesenvolvidos e desenvolvidos. Nessa situação, os países dependentes obtêm empréstimos dos países ricos para garantir o desenvolvimento. $\mathrm{O}$ pagamento desta dívida dá-se em dólares que é a moeda dos países ditos tecnológicos. Para isso, os países pobres, deixam de plantar alimentos para fazer o plantio de produtos exportáveis a base de grãos que têm os seus preços reduzidos a cada ano. Estes produtos em sua maioria são para abastecer os animais dos países ricos. Esse processo faz com que haja um encarecimento dos alimentos, e enfim um empobrecimento da população, principalmente, do grupo social mais pobre (favelado). Este encarecimento é fruto da relação mercado-produto, ou seja, da redução da produção de alimentos que se torna cada vez mais caro para a mesa da classe pobre no país. A agricultura predominante é o 'plantation comercial' para a exportação, que gera o aumento dessa produção pelos países pobres, com conseqüente diminuição no valor de mercado desses produtos. Esse processo gera desigualdades, pobreza e uma maior agressão ao meio ambiente, pois a pobreza econômica e educacional tem relação com a pobreza ecológica.

Gore (1993) comenta que a corrupção favorece a degradação e dificulta a relação política dos governantes com o meio-ambiente. Isso ocorre porque um sistema político corrompido não funciona bem, na medida em que, diminuirão a sua atuação jurídica, fiscalizatória e administrativa acerca das questões ambientais. O político, o empregado público e as forças policiais ficarão alheios aos impactos ambientais, pois estão pactuados com a corrupção. Os corruptores, no geral, empresários de cunho imediatista e de olho no lucro em conluio com os corruptos do Estado fazem aumentar ainda mais a situação socioeconômica do país. Nesse jogo de disputa, a sociedade é que sairá perdendo, pois terá que conviver com um meio ambiente desequilibrado, poluído, contaminado e degradado, enquanto que, na maioria das vezes, estes empresários e a elite como um todo moram em bairros bem arborizados, condomínios fechados (verdadeiros oásis). O lucro dessa situação, porém, fica com uma parcela bem pequena da sociedade (burguesia abastada e desumana) restando aos pobres a falta de tudo, inclusive, de um ambiente equilibrado.

Afirma Gore (1993) a necessidade urgente de instituir uma ação recíproca entre direitos e responsabilidades na questão ecológica. Neste sentido, a democracia dá-se através 


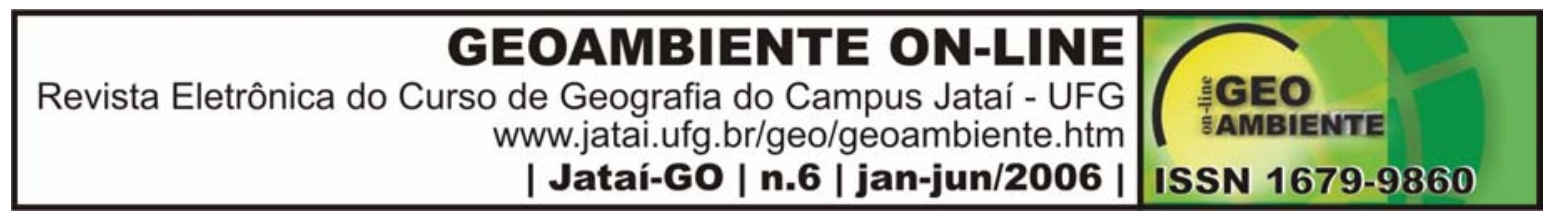

de direitos, mas também de responsabilidades. A sociedade, no geral, tem os seus direitos atingidos, principalmente no que tange ao meio ambiente equilibrado, pois convivemos com a poluição, alteração da paisagem natural e outros tipos de degradação ambiental devido às construções, a implantação de usinas hidrelétricas, as indústrias e as pavimentações de rodovias e ruas urbanas tanto por parte do governo como por particulares. Somente, com os relatórios de impactos ambientais e outras ações de mitigação poderemos reduzir os impactos ao meio ambiente. Essa ganância por lucros rápidos é, na maioria das vezes, fruto de políticas imediatistas de governos e empresas particulares que abusam de seus direitos de investir e produzir, depreciando os direitos do coletivo. Ao poluir e degradar o meio ambiente estamos prejudicando a sociedade no seu direito elementar que é o direito ao ambiente equilibrado.

Penteado (2000) aponta a contradição entre a palavra Desenvolvimento e Sustentabilidade, afinal, como empregá-las juntas, ou seja, na perspectiva do desenvolvimento sustentável? A palavra Desenvolvimento está voltada para o progresso, a riqueza, e não, à melhoria da qualidade de vida da população. E o termo sustentável estabelece uma relação de equilíbrio entre as necessidades humanas e o suporte de recursos naturais. Este equilíbrio demonstra a preocupação com as populações atuais e as futuras gerações quanto ao aporte de recursos naturais. Afinal, como instituir o desenvolvimento (progresso e riqueza), retirando os recursos naturais para alimentar um hábito consumista e perverso da sociedade moderna e, ao mesmo tempo, preocupar-se com a sustentabilidade da natureza? Como utilizar e extrair os recursos da natureza de forma sustentável, ou seja, (des) envolver e ao mesmo tempo envolver com a natureza sem destruí-la? Então, está lançado o desafio de desenvolver no envolvimento (desenvolvimento sustentável). Sabemos que na prática isto é difícil, pois o exemplo que nos cerca é de um desenvolvimento distanciado (crescimento econômico) dos envolvimentos com a vida, com a humanidade e com a natureza.

Então torna necessário promover os RS (DIAS, 2002b: 78).

- Respeito ao próximo;

- responsabilidade por suas ações; 


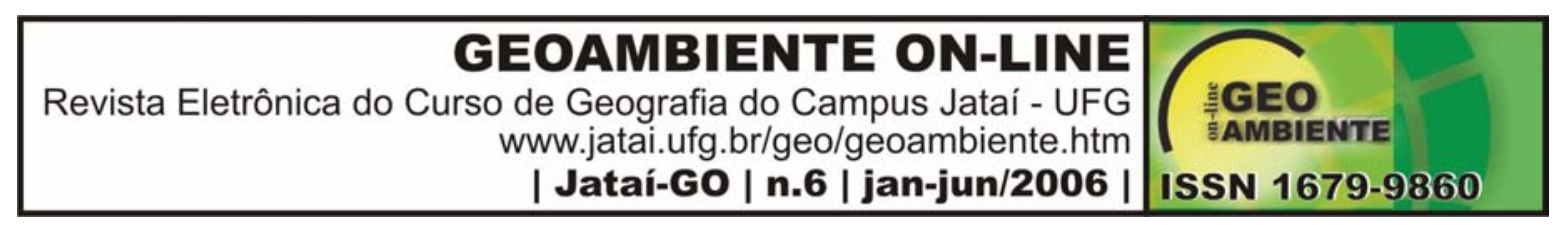

- reduzir o consumo;

- reciclar e preciclar;

- replanejar.

Conseqüentemente, há a necessidade de se desenvolver as seguintes atividades intersetoriais (DIAS, 2002b: 78).

- racionalização do uso da água;

- racionalização do uso de combustíveis fósseis;

- compostagem;

- reflorestamento;

- oficina de reaproveitamento;

- preciclagem;

- coleta seletiva e reciclagem.

"Contudo precisamos ir além da reciclagem para a 'simbiose industrial', em que o resíduo de uma empresa se torna o insumo de outra" (DIAS, 2002b: 78).

De forma prudente, Penteado (2000) discute as controvérsias entre produção e desenvolvimento, pois fica clara, a interdependência de ambos na história do capitalismo mundial. Foi a partir da produção industrial que os países Europeus, e depois a América do Norte e Japão tornaram-se países "Desenvolvidos". Esse processo instigou os países pobres e dependentes de tecnologia a entrar nesta "ciranda" do Desenvolvimento. Estes países não estavam preparados "nem politicamente, nem socialmente e nem intelectualmente" (grifo nosso) para assumir uma industrialização rápida e tardia. Houve um "falso" desenvolvimento que levou os países subdesenvolvidos a gerar sérios problemas socioambientais nos espaços rurais e urbanos. Nos espaços rurais, a mecanização, a partir de 1965, expulsou os trabalhadores analfabetos do campo para as cidades contribuindo para a "favelização e degradação do meio ambiente urbano e também do ser humano (falta de condições mínimas de sobrevivência)" (grifo nosso). Diante do exposto, será que podemos afirmar que um país é desenvolvido somente tomando por base o crescimento econômico? 


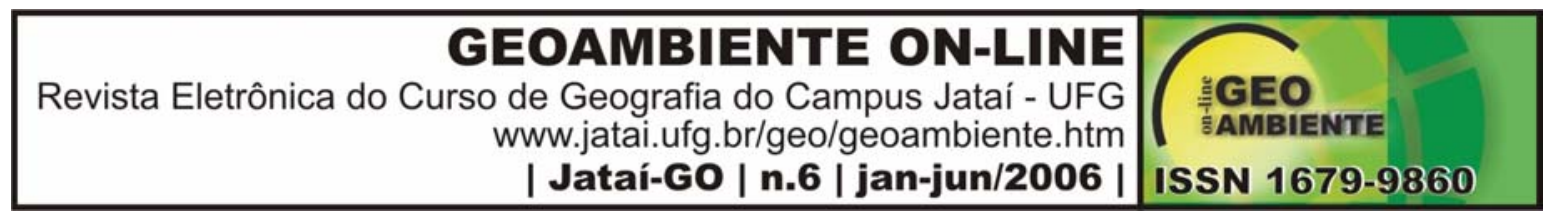

De todos os elementos formadores de alterações ambientais globais, o consumismo, $o$ crescimento populacional e a crescente ampliação global dos ecossistemas urbanos continuam em sua trajetória de colisão. Essa expansão, em sua maioria, vem sendo acompanhada por perdas crescentes de qualidade de vida e aumento da pressão ambiental sobre os recursos naturais (DIAS, 2002a: 33).

O Desenvolvimento conseguido pelos países do Norte é perverso, é desumano com os países periféricos, na medida em que produziu um circulo de pobreza, miséria, exploração e degradação ambiental nos países do sul, apesar de existir nos países Desenvolvidos o "Estado do Bem Estar Social". Sendo assim, ficou evidente que esse desenvolvimento não teve envolvimento com a natureza, com a humanidade e com os animais, pois os níveis de degradação nestes países e nos países explorados para suprir a sua "máquina consumista" são altíssimos e vergonhosos do ponto de vista humanitário e da sustentabilidade do nosso planeta.

O interesse da lógica capitalista é, à primeira vista, o mais desagradável e antipático porque é voltado imediatamente para o lucro [...] meta maximizar o lucro, a lógica capitalista impulsionou a pesquisa e a produção do saber especializado [...] o avanço nos conhecimentos náuticos colocou uma sociedade (a portuguesa) que já conhecia o modo de vida urbana e vivia uma economia de mercado (produção para a troca, visando o lucro) em contato com outra sociedade que se organizava em comunidades rurais e vivia uma economia de subsistência (voltada apenas para a satisfação de suas necessidades) [...] o valor conferido pela lógica capitalista ao desenvolvimento da ciência, com o conseqüente prestígio atribuído à tecnologia, colocou na mão dos técnicos e dos especialistas um grande poder de decisões, ou seja, um grande poder político (PENTEADO, 2000, p. 86-89).

Ainda no estudo da questão socioambiental, Penteado (2000) aponta o contraponto entre biodiversidade e biotecnologia, sendo que, aquela está concentrada nos países pobres e esta faz parte do "Know-how" e das tecnologias de ponta que são vendidas através de "Royalties" aos países pobres em conhecimento tecnológico. O principal fator da dualidade 


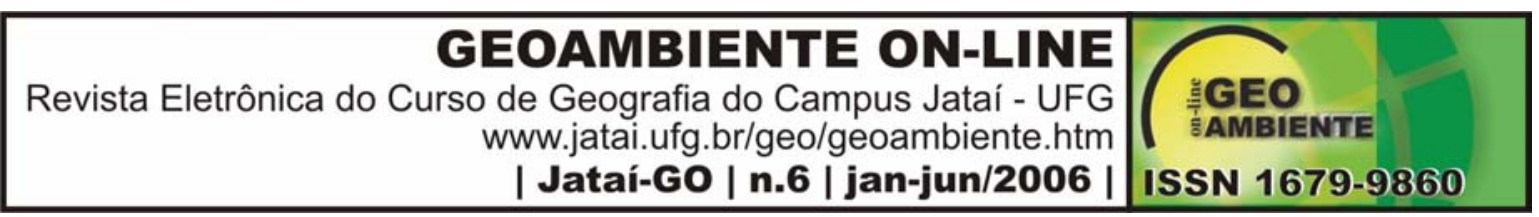

parte do não reconhecimento da patente sobre a biodiversidade, e somente patenteia-se a biotecnologia através da manipulação. Há uma supervalorização do conhecimento científico e por outro lado, a desvalorização da biodiversidade e do conhecimento tradicional dos povos que habitam os espaços de biodiversidade dos países pobres. Esse processo acirra, cada vez mais, o desenvolvimento humano, social, cultural e ambiental dos países subdesenvolvidos na medida em que terão que comprar os produtos manipulados de sua biodiversidade, pelos países desenvolvidos. "A biodiversidade faz parte do fármaco do presente e do futuro, sendo assim faz parte da 'patente da vida'. Nessa lógica, há necessidade urgente de valorizar a nossa biodiversidade, pois só assim começaremos a desenvolver com envolvimento, principalmente, com a justiça social" (grifo nosso).

Segundo Penteado (2000) para desmascarar esses contrapontos é preciso ampliar o acesso da população à cidadania e à educação. Pois, somente assim poderemos buscar a tão sonhada justiça social, ambiental, cultural e política.

A cidadania diz respeito a um estado de direito que ganha corpo nas sociedades em que a organização política (o poder de tomar decisões e de administrar a vida pública) se orienta por princípios democráticos [...] tais princípios, a população como um todo [...] tem o direito de participar das tomadas de decisões e da administração da vida pública, seja indiretamente por intermédio de representantes por ela própria escolhidos, seja diretamente através de formas organizadas de participação coletiva nestas tarefas [...] (PENTEADO, 2000, p. 23).

\section{Desenvolvimento Sustentável na perspectiva da "pegada ecológica" (Dias, 2002a).}

“O Desenvolvimento Sustentável só é atingido com justiça social. (DIAS, 2002b: 65). Não existirá uma sociedade humana sustentável sem uma educação renovadora" (DIAS, 2002b: 67). "A Educação Ambiental sensibiliza as pessoas sobre o meio ambiente (como funciona, como dependem dele e como o afetam), levando-as a participar ativamente de sua defesa e melhoria" (DIAS, 2002b: 67). "A Educação atual promove a desconexão, 'treina' as pessoas para que ignorem as conseqüências ambientais de seus atos" (DIAS, 2002b: 67). Nesse enfoque apontaremos os destaques principais da boa convivência com a natureza. 


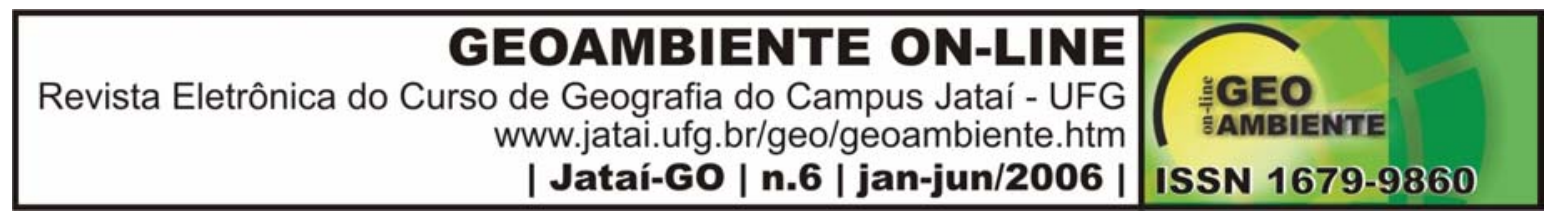

O ser humano precisa modificar o quadro de insustentabilidade existente no planeta. Para tanto, será necessário descobrir um novo estilo de vida baseado em uma ética global, resgatar e criar novos valores e repensar e modificar os seus hábitos de consumo. Precisa-se viabilizar o desenvolvimento sustentável. A Educação Ambiental é o instrumento principal para processar essas transformações (DIAS, 2002b: 68).

Currie et al. (1998) mostra que precisamos de três necessidades básicas para a sobrevivência de nossa espécie: ar, água e solo. Mas, atualmente, estão sendo contaminados por diversos poluentes pelo próprio homem. Esse processo não pode continuar! Senão, não terá vida na terra em um curto espaço de tempo.

Dias (2002a) mostra que há poucos estudos discutindo a questão socioambiental nos ambientes urbanos. "Chega a ser inacreditável a forma como o ambiente urbano é desconsiderado em estudos ecológicos" (DIAS, 2002a: 31).

O desafio evolucionário humano está ocorrendo nos centros urbanos. As cidades são pontos emanadores de indução de alterações ambientais globais. Quase todo o crescimento está ocorrendo em cidades. Elas ocupam apenas $2 \%$ da superfície da terra, mas consomem $75 \%$ dos seus recursos. As cidades tendem a ocupar o mesmo nicho global dentro da biosfera e explorar os recursos da mesma maneira. Esse modelo suicida está sendo replicado em quase todo o mundo, gerando pressões cada vez mais fortes. O aumento da eficiência em uma parte relativamente pequena do mundo produziria grandes resultados (DIAS, 2002a: 15).

De acordo com este modelo de vida, Dias (2002a) mostra que a "Pegada Ecológica" faz parte do espaço destinado a produzir, a sustentar as necessidades apontadas pelo consumo orientado por um estilo de vida ditado pela mídia. Esse espaço terá que assimilar os resíduos lançados ao meio ambiente. Rees (1990 e 1998) apud Dias (2002) discute a relação desprorpocional entre a área da cidade e a área necessária para abastecê-la. A área de sustentação da cidade é superior a sua área urbana, o que, produzirá um "déficit 


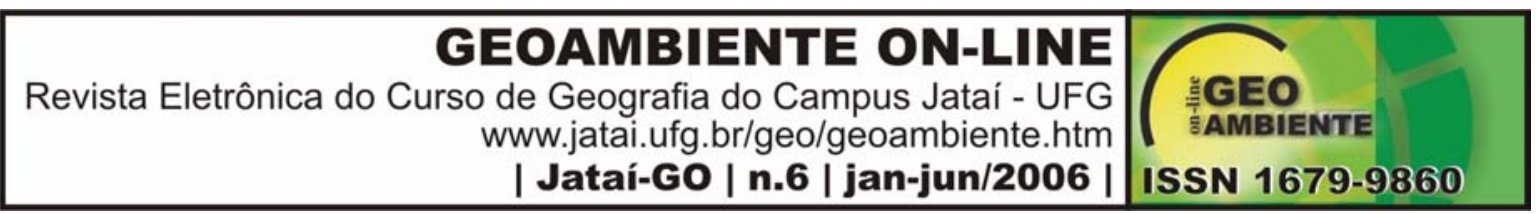

ecológico". Então, cidades como São Paulo, precisam de uma área maior que a sua área urbana para satisfazer o consumo desta cidade.

A expansão dos ecossistemas urbana é acompanhada por incríveis aumentos de consumo energéticos, dissipação de calor, impermebialização de solos, alterações microclimáticas, fragmentação e destruição de hábitats, expulsão e/ou eliminação de espécimes da flora e da fauna acumulação de carbono, poluição atmosférica e sonora, aumento da concentração de ondas eletromagnéticas, além de uma fabulosa produção de resíduos sólidos, líquidos e gasosos, inconvenientemente despejados na atmosfera, nos corpos d' água e nos solos (DIAS, 2002a: 32).

Dias (2002a) esclarece o "viés etnocêntrico" representado na abordagem apontada pelo Desenvolvimento sustentável, como aquele que: "satisfazer as necessidades das gerações presentes, sem comprometer as gerações futuras" (DIAS, 2002a: 23). Essa situação nos permite dizer que há uma ganância das gerações presentes, pois os recursos naturais terão que satisfazer suas necessidades sem uma gradual redução e avaliação do nível de consumo da cultura moderna frente aos recursos.

\section{Conclusão}

Então, concluímos este trabalho com a convicção de que tentamos apontar a dualidade entre o desenvolvimento e crescimento. Na maioria das vezes, pois, um país é desenvolvido em uma parte do processo (econômico), mas existem outras etapas a seguir, como: ambiental, social, cultural e política. E só haverá realmente Desenvolvimento quando se atender a todos estes pontos. Há no planeta os países ricos que são ditos "Desenvolvidos" e que não são, pois exploram os países pobres, degradam o meio ambiente, subjugam as culturas mais fracas. O verdadeiro Desenvolvimento concretiza-se pelo envolvimento com a natureza e com a humanidade, pois só assim existirá a vida. Sem essa conexão não há vida, nem Desenvolvimento, nem riqueza, nem pobreza e nem mundo.

\section{Referências Bibliográficas}


GEOAMBIENTE ON-LINE
Revista Eletrônica do Curso de Geografia do Campus Jatai - UFG www.jatai.ufg.br/geo/geoambiente.htm | Jataí-GO | n.6 | jan-jun/2006 || ISSN 1679-9860

CURRIE, Karen L; et al. Meio Ambiente: Interdisciplinaridade na Prática. $5^{\text {a }}$ ed. Campinas: SP. Papirus, 184p. 1998.

DIAS, Genebaldo Freire. Pegada Ecológica e Sustentabilidade Humana. São Paulo: Gaia, 257p. 2002(a).

DIAS, Genebaldo Freire. Iniciação à Temática Ambiental. São Paulo: Gaia, 110p. 2002(b). GORE, Albert. A terra em Balanço: a ecologia e o espírito humano. Tradução Elenice Mazzilli. São Paulo: Augustus, 447p. 1993.

MÜLLER, Geraldo. Complexo Agroindustrial e Modernização Agrária. São Paulo: Educ e HUCITEC, 149p. 1989.

PENTEADO, Heloísa Dupas. Meio Ambiente e Formação de Professores. $3^{\text {a }}$ ed. São Paulo: Cortez, (coleção Questões da nossa época; v.38). 120p. 2000. 